\title{
Renal protective effects of zingerone in a mouse model of sepsis
}

\author{
Bong-Seon Lee ${ }^{1, \#}$, Changhun Lee ${ }^{1, \#}$, Sumin Yang ${ }^{1}$, Sae-Kwang Ku ${ }^{2, *} \mathcal{E} J o n g-S u p ~ B a e^{1, *}$ \\ ${ }^{1}$ College of Pharmacy, CMRI, Research Institute of Pharmaceutical Sciences, BK21 Plus KNU Multi-Omics based Creative Drug Research \\ Team, Kyungpook National University, Daegu 41566, ${ }^{2}$ Department of Histology and Anatomy, College of Korean Medicine, Daegu Haany \\ University, Gyeongsan 38610, Korea
}

\begin{abstract}
Zingerone (ZGR), a phenolic alkanone isolated from ginger, has been reported to possess pharmacological activities such as anti-inflammatory and anti-apoptotic effects. This study was initiated to determine whether ZGR could modulate renal functional damage in a mouse model of sepsis and to elucidate the underlying mechanisms. The potential of ZGR treatment to reduce renal damage induced by cecal ligation and puncture (CLP) surgery in mice was measured by assessment of serum creatinine, blood urea nitrogen (BUN), lipid peroxidation, total glutathione, glutathione peroxidase activity, catalase activity, and superoxide dismutase activity. Treatment with ZGR resulted in elevated plasma levels of BUN and creatinine, and of protein in urine in mice with CLP-induced renal damage. Moreover, ZGR inhibited nuclear factor- $K B$ activation and reduced the induction of nitric oxide synthase and excessive production of nitric acid. ZGR treatment also reduced the plasma levels of interleukin-6 and tumor necrosis factor- $\alpha$, reduced lethality due to CLP-induced sepsis, increased lipid peroxidation, and markedly enhanced the antioxidant defense system by restoring the levels of superoxide dismutase, glutathione peroxidase, and catalase in kidney tissues. Our study showed renal suppressive effects of zingerone in a mouse model of sepsis, suggesting that ZGR protects mice against sepsis-triggered renal injury. [BMB Reports 2019; 52(4): 271-276]
\end{abstract}

\section{INTRODUCTION}

As a systemic inflammatory response syndrome (SIRS), sepsis

*Corresponding authors. Sae-Kwang Ku, Tel: +82-53-819-1549; Fax: +82-53-819-1860; E-mail: gucci200@hanmail.net; Jong-Sup Bae, Tel: +82-53-950-8570; Fax: +82-53-950-8557; E-mail: baejs@ knu.ac.kr

${ }^{\#}$ These authors contributed equally to this work.

https://doi.org/10.5483/BMBRep.2019.52.4.175

Received 27 July 2018, Revised 13 August 2018, Accepted 30 August 2018

Keywords: Antioxidant, Renal injury, Renal toxicity, Sepsis, Zingerone is caused by viral infection and accounts for one-third of in-hospital deaths $(1,2)$. In response to viral infection, the activation of cytokines is one of host defense systems, however, uncontrolled or over-production of cytokines can cause overall tissue damages and multiple organ failure (3). Inducible nitric oxide synthase (iNOS) is activated, blood level of nitric oxide (NO) and the synthesis of reactive oxygen species (ROS) are increased by CLP, which resulted in the cytotoxicity $(4,5)$. Therefore, the degree of organ failure can be reduced by inhibiting inflammatory cytokines and iNOS activity (4-6). Noting that the inhibiting the production of ROS and inflammatory cytokines is associated with the therapeutic functions in sepsis $(7,8)$, drug candidates capable of reducing cytokine production and ROS can also prevent or alleviate the pathological cascade of inflammation caused by sepsis.

Zingiber officinale is known to have beneficial properties such as antioxidative, anticancer, and anti-inflammatory activities (9). As an active compound of ginger rhizome (10), Zingerone (ZGR) has a variety of biological functions, including anti-apoptosis and anti-inflammation and protective responses against myocardial infarction and irritable bowel disorder (11-15). However, to our knowledge, the possible protective effects ZGR against renal damage have not been studied. In the current study, we seek to remedy this deficit by investigating the renal protective effects of ZGR in an animal sepsis model.

\section{RESULTS}

ZGR reduced CLP-induced renal tissue injury and the production of nitrate in renal tissue after CLP

Previous reports showed that treatment of cells or mice with ZGR inhibited LPS-induced expression and activity of sPLA2-IIA which contributes to vascular inflammation (16) and ZGR has anti-platelet aggregation activity (17). In those studies, ZGR was used from at $10 \mu \mathrm{M}$ to $50 \mu \mathrm{M}$ in human endothelial cells and from at $0.14,0.36$, or $0.72 \mathrm{mg} / \mathrm{kg}$ in mice $(16,17)$. Therefore, in this study, ZGR was also used from 0.07 to $0.72 \mathrm{mg} / \mathrm{kg}$.

Table 1 showed the changes of nephrotoxic markers and urine protein levels by CLP; after 4 days CLP, the blood levels of BUN and creatinine, and urine protein were increased,

ISSN: 1976-670X (electronic edition)

Copyright (C) 2019 by the The Korean Society for Biochemistry and Molecular Biology

(c) This is an open-access article distributed under the terms of the Creative Commons Attribution Non-Commercial License (http://creativecommons.org/licenses/by-nc/4.0) which permits unrestricted non-commercial use, distribution, and reproduction in any medium, provided the original work is properly cited. 
Table 1. Effects of ZGR treatment on plasma levels of BUN and creatinine and urine level of protein in CLP-operated mice ${ }^{a}$

\begin{tabular}{|c|c|c|c|c|}
\hline & BUN (mg/dl) & Creatinine (mg/dl) & Urine protein (mg/12 hour) & $\mathrm{LDH}(\mathrm{U} / \mathrm{dl})$ \\
\hline Sham & $17.2 \pm 1.1$ & $0.118 \pm 0.011$ & $2.2 \pm 0.15$ & $291 \pm 23.3$ \\
\hline ZGR $(0.72 \mathrm{mg} / \mathrm{kg})$ & $18.1 \pm 0.9$ & $0.121 \pm 0.017$ & $2.3 \pm 0.28$ & $285 \pm 23.6$ \\
\hline CLP & $78.4 \pm 6.3$ & $0.489 \pm 0.035$ & $14.1 \pm 0.89$ & $3520 \pm 255.2$ \\
\hline $\mathrm{CLP}+\mathrm{ZGR}(0.07 \mathrm{mg} / \mathrm{kg})$ & $77.5 \pm 5.1$ & $0.492 \pm 0.031$ & $13.8 \pm 0.55$ & $3495 \pm 205.6$ \\
\hline CLP + ZGR $(0.14 \mathrm{mg} / \mathrm{kg})$ & $65.2 \pm 5.2^{*}$ & $0.325 \pm 0.023^{*}$ & $8.5 \pm 0.57^{*}$ & $2584 \pm 189.5^{*}$ \\
\hline CLP + ZGR $(0.29 \mathrm{mg} / \mathrm{kg})$ & $47.1 \pm 3.5^{*}$ & $0.288 \pm 0.023^{*}$ & $5.3 \pm 0.41^{*}$ & $1875 \pm 156.7^{*}$ \\
\hline CLP + ZGR (0.72 mg/kg) & $29.7 \pm 2.2^{*}$ & $0.231 \pm 0.022^{*}$ & $3.5 \pm 0.22^{*}$ & $1285 \pm 105.4^{*}$ \\
\hline
\end{tabular}

${ }^{\mathrm{a}}$ Each value represents the mean $\pm \mathrm{SD}(\mathrm{n}=10)$.

Sham, sham-operated mice; ZGR, mice treated with ZGR (0.72 mg/kg body weight) at 12 and 50 h; CLP, CLP-operated mice; ZGR + CLP, mice treated with ZGR at 12 and $50 \mathrm{~h}$ after CLP surgery.

$* P<0.05$ as compared to CLP.

Table 2. Effects of ZGR treatment on NO, TNF- $\alpha$, IL-6 levels and renal MPO activity in CLP-operated mice ${ }^{\mathrm{a}}$

\begin{tabular}{lccc}
\hline & NO $(\mu \mathrm{M})$ & TNF- $\alpha(\mathrm{pg} / \mathrm{ml})$ & IL-6 (pg/ml) \\
\hline Sham & $32.52 \pm 2.35$ & $125.69 \pm 10.21$ & $0.85 \pm 0.05$ \\
ZGR $(0.72 \mathrm{mg} / \mathrm{kg})$ & $34.26 \pm 3.11$ & $135.69 \pm 12.38$ & $0.67 \pm 0.04$ \\
CLP & $231.62 \pm 15.98$ & $582.35 \pm 29.65$ & $85.61 \pm 4.95$ \\
CLP + ZGR $(0.07 \mathrm{mg} / \mathrm{kg})$ & $225.57 \pm 20.31$ & $548.25 \pm 32.65$ & $86.39 \pm 5.15$ \\
CLP + ZGR $(0.14 \mathrm{mg} / \mathrm{kg})$ & $174.36 \pm 15.37^{*}$ & $358.24 \pm 25.96^{*}$ & $62.27 \pm 2.58^{*}$ \\
CLP + ZGR $(0.29 \mathrm{mg} / \mathrm{kg})$ & $135.29 \pm 12.17^{*}$ & $304.58 \pm 25.65^{*}$ & $35.21 \pm 3.58^{*}$ \\
CLP + ZGR $(0.72 \mathrm{mg} / \mathrm{kg})$ & $92.28 \pm 8.57^{*}$ & $189.51 \pm 12.38^{*}$ & $25.14 \pm 2.39^{*}$ \\
\hline
\end{tabular}

${ }^{\mathrm{a}}$ Each value represents the mean $\pm \mathrm{SD}(\mathrm{n}=10)$.

Sham, sham-operated mice; ZGR, mice treated with ZGR (0.72 mg/kg body weight) at 12 and 50 h; CLP, CLP-operated mice; ZGR + CLP, mice treated with ZGR at 12 and $50 \mathrm{~h}$ after CLP surgery.

$* P<0.05$ as compared to CLP.

which was significantly inhibited by the treatment of ZGR (two equal doses of ZGR, one at $12 \mathrm{~h}$ and the other at $50 \mathrm{~h}$ after CLP). However, there was no change in sham-operated or ZGR-only treated groups (Table 1). In addition, $\mathrm{LDH}$, a general tissue injury marker, was also reduced by ZGR.

Next, we determined the effects of ZGR on the production of $\mathrm{NO}$ by measuring the stable end product of $\mathrm{NO}$ (nitrate levels) in vivo. Table 2 indicated that mouse plasma NO production was significantly increased by CLP (7-fold), which was reduced by ZGR treatment (upto $39 \%$ ).

\section{ZGR reduced CLP-induced inflammatory responses and lipid peroxidation in renal tissue after CLP}

We tested whether ZGR treatment could ameliorate the production of inflammatory mediator, such as TNF- $\alpha$ and IL-6, in CLP-induced mice. Table 2 showed that blood levels of TNF- $\alpha$ and IL- 6 were dramatically increased by CLP, which was inhibited by ZGR. In order to determine the effects of ZGR on the infiltration of leukocytes in renal tissue after CLP, we determined the MPO level after CLP. Table 2 indicated that ZGR inhibited upregulated MPO concentration by CLP.
Moreover, during inflammatory response, inflammatory mediator proteins expression and MAPKs signaling pathways are closely involved in the regulation of inflammatory response. Therefore, we determined the effects of ZGR on the transcriptional regulation of cyclooxygenase (COX)-2 and mitogen-activated protein kinase (MAPK) such as p38 and janus kinase (JNK). Data showed that ZGR inhibited CLP-mediated expressions of COX-2, p38, and JNK (Supp. Table 1). ZGR also reduced the concentration of MDA, as a marker of lipid peroxidation (Table 3).

\section{ZGR ameliorated CLP-induced oxidative stress in renal tissue after CLP}

We tested the possible beneficial effects of ZGR on CLP-induced oxidative stress by measuring the antioxidant $\mathrm{GSH}$ and the oxidative stress associated enzymes superoxide dismutase (SOD), glutathione peroxidase (GSH-Px), and catalase (CAT). As shown in Table 3, total GSH levels and the activities of SOD, GSH-Px, and CAT were not changed in ZGR-only treated or sham-operated mice. However, postsurgery treatment with ZGR increased total GSH and renal 
Table 3. Effects of ZGR treatment on MDA level and the activities of renal antioxidant enzymes in CLP-operated mice ${ }^{\mathrm{a}}$

\begin{tabular}{|c|c|c|c|c|c|}
\hline & MDA (nMmg protein) & GSH (nM/mg protein) & SOD (U/mg protein) & GSH-Px (U/mg protein) & CAT (U/mg protein) \\
\hline Sham & $189.31 \pm 11.65$ & $26.37 \pm 2.02$ & $1.11 \pm 0.03$ & $2.38 \pm 0.19$ & $4.31 \pm 0.25$ \\
\hline ZGR (0.72 mg/kg) & $191.57 \pm 15.68$ & $28.05 \pm 1.89$ & $1.09 \pm 0.05$ & $2.41 \pm 0.24$ & $4.52 \pm 0.33$ \\
\hline CLP & $325.69 \pm 30.25$ & $16.89 \pm 1.41$ & $0.72 \pm 0.05$ & $1.35 \pm 0.12$ & $2.95 \pm 0.29$ \\
\hline CLP + ZGR (0.07 mg/kg) & $318.72 \pm 27.68$ & $17.05 \pm 1.68$ & $0.74 \pm 0.06$ & $1.37 \pm 0.11$ & $2.89 \pm 0.22$ \\
\hline CLP + ZGR (0.14 mg/kg) & $260.17 \pm 18.98^{*}$ & $21.08 \pm 1.85^{*}$ & $0.82 \pm 0.07^{*}$ & $1.78 \pm 0.11^{*}$ & $3.51 \pm 0.31^{*}$ \\
\hline CLP + ZGR (0.29 mg/kg) & $224.58 \pm 18.68^{*}$ & $23.58 \pm 2.32^{*}$ & $0.89 \pm 0.05^{*}$ & $1.92 \pm 0.14^{*}$ & $3.95 \pm 0.25^{*}$ \\
\hline CLP + ZGR (0.72 mg/kg) & $201.15 \pm 17.52^{*}$ & $24.85 \pm 2.62^{*}$ & $0.94 \pm 0.08^{*}$ & $2.14 \pm 0.15^{*}$ & $4.15 \pm 0.28^{*}$ \\
\hline
\end{tabular}

${ }^{\mathrm{a}}$ Each value represents the mean $\pm \mathrm{SD}(\mathrm{n}=10)$.

Sham, sham-operated mice; ZGR, mice treated with ZGR (0.72 mg/kg body weight) at 12 and 50 h; CLP, CLP-operated mice; ZGR + CLP, mice treated with ZGR at 12 and $50 \mathrm{~h}$ after CLP surgery.

$* P<0.05$ as compared to CLP.

enzyme activities (Table 3). Moreover, ZGR suppressed the transcriptional expression levels of SOD, GSH-Px, and CAT by CLP (Supplemental Table 1). Noting that nuclear factorerythroid 2-related factor 2 (Nrf2) is a potential pathway to protective responses against oxidative stress, and heme oxygenase-1 (HO-1) is one of the most important enzymes for antioxidant pathway $(18,19)$. Therefore, we determined the effects of ZGR on the induction of HO-1 and on the nuclear accumulation of Nrf2. Data showed that HO-1 protein expression was induced by ZGR (Fig. 1A) and ZGR mediated the translocation of Nrf2 from the cytosol to nucleus in a concentration-dependent manner (Supplemental Fig. 1). Therefore, these results indicate that the Nrf2/HO-1 signaling axis plays an important role in the anti-oxidant effects of ZGR.

\section{ZGR reduced iNOS level and translation of NF-KB p65}

We determined the underlying mechanisms of the antiinflammatory responses of ZGR by measuring levels of iNOS, $I \kappa B$, and NF- $\kappa B$ proteins in kidney tissues of the mice. Post-treatment with ZGR reduced increased levels of iNOS protein by CLP (Fig. 1B). And, we tested whether ZGR could control the degradation of IKB by CLP and translocation of the subunit of NF-KB p65 from the cytosol to the nucleus. As shown in Fig. $1 \mathrm{~B}$, the translocation of nuclear factor (NF)- $\mathrm{KB}$ p65 to nucleus and activation of NF-KB p65 in nucleus and I inhibitory kappa B (ІКB) phosphorylation in kidney significantly increased after CLP. Moreover, ZGR administration after CLP decreased NF- $\kappa B$ p65 activation and I $\mathrm{B}$ phosphorylation compared with the CLP group. In addition, degradation of IKB was lower in the ZGR + CLP group than in the CLP-only group (Fig. 1B).

\section{ZGR reduced CLP-induced lethality}

In order to prove the beneficial responses of ZGR in renal tissues, we determined the effects of ZGR on CLP-induced lethality. To do this, ZGR (one at $12 \mathrm{~h}$ and the other $50 \mathrm{~h}$ after CLP) was injected intravenously. As shown in Fig. 1C, ZGR treatment increased the rate of survival of mice with sepsis

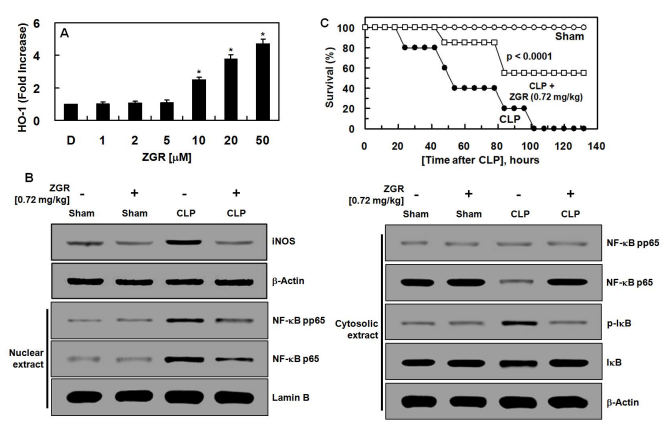

Fig. 1. Effects of ZGR treatment on the expression levels of HO-1 in HUVECs, renal iNOS, IKB and NF- $\kappa B$ expression in CLP-operated mice and on CLP-induced septic lethality. (A) HUVECs were harvested after treatment with aloin $(0-50 \mu \mathrm{M})$ for $16 \mathrm{~h}$. The extracted proteins were subjected to ELISA for $\mathrm{HO}-1$ expression. (B) Sham, sham-operated mice; Sham + ZGR, mice treated with ZGR $(0.72 \mathrm{mg} / \mathrm{kg}$ body weight $)$ at 12 and $50 \mathrm{~h}$ after sham operation. CLP, CLP-operated mice; CLP + ZGR, mice treated with ZGR $(0.72 \mathrm{mg} / \mathrm{kg}$ body weight) at 12 and $50 \mathrm{~h}$ after CLP surgery (from left line). Western blots of iNOS, phosphor-l $\kappa B$, $I \kappa B$, phosphor-NF- $\kappa B$, NF- $\kappa B$, Lamin-B, and $\beta$-actin. The image is representative of results obtained from three different experiments. (C) Male C57BL/6 mice $(\mathrm{n}=20)$ were administered ZGR at $0.72 \mathrm{mg} / \mathrm{kg}$ (i.v. $\square$ ) at $12 \mathrm{~h}$ and $50 \mathrm{~h}$ after CLP. Animal survival was monitored every $12 \mathrm{~h}$ for $132 \mathrm{~h}$ after CLP. Control CLP mice ( ) and sham-operated mice $(\bigcirc)$ were administered sterile saline $(n=20)$. Kaplan-Meier survival analysis was used to determine the overall survival rates versus CLP treated mice. $\mathrm{D}=0.2 \%$ DMSO is the vehicle control. ${ }^{*} \mathrm{P}<0.05$ versus DMSO (A).

(55\%), according to a Kaplan-Meier survival analysis ( $\mathrm{P}<$ 0.0001). The marked improvement in survival rate achieved by the treatment suggested that ZGR might be of value in therapies for severe vascular inflammatory diseases, such as sepsis and septic shock.

\section{DISCUSSION}

The purpose of this study was to test the beneficial effect of 
ZGR, an active compound isolated from C. tricuspidata on renal injury in CLP-induced septic mice. Data showed that treatment with ZGR after CLP surgery dramatically improved CLP-induced renal damages. Moreover, the elevated levels of TNF- $\alpha$, IL- 6 , NO, iNOS, and MPO by CLP was inhibited by ZGR. These improved effects were associated with an increase in the activity of the antioxidant enzyme and a reduction in the level of lipid peroxidation products in the kidney tissue. The molecular mechanism of beneficial effects of ZGR is mediated by the suppression of NF-kB activation. Consistent with previous reports (20-22), urine protein excretion, plasma BUN and creatinine levels were increased by CLP. In our study we also found that a change in kidney function after CLP surgery could be improved by ZGR because a significant inhibition in BUN, creatinine and urine protein levels was confirmed.

Under inflammatory condition, released $\mathrm{NO}$ is a pivotal inflammatory molecule and iNOS is induced and then NO is synthesized, which could influence the inflammation pathway (8). Noting that CLP-mediated kidney inflammatory injury is due to an increase in iNOS activity and consequently abnormal NO levels (4-6), our data suggested that ZGR inhibited CLP-induced NO production and iNOS expression in renal tissue.

It is well known that IL- 6 and TNF- $\alpha$ are the major player in severe inflammatory conditions $(3,23)$. Based on the current findings that ZGR reduced the levels of both inflammatory regulators, IL- 6 and TNF- $\alpha$, ZGR could affect the crucial point of pathogenesis in the inflammation diseases. Since NF-KB is involved in the expression of inflammatory genes, it is a potential target for treating various inflammatory diseases (24). Here, we showed that the activation of NF-KB by CLP, which was inhibited by ZGR, indicating that the upregulated levels of iNOS, TNF- $\alpha$, and IL- 6 by CLP, as least in part, were affected by the interaction between ZGR and NF-кB. Recently, we reported the anti-septic effects of ZGR on high mobility group box 1 (HMGB1), a late mediator of sepsis, -mediated severe vascular inflammatory responses (11). We showed that ZGR reduced HMGB1 release in bacterial lipopolysaccharideactivated human endothelial cells, inhibited HMGB1-mediated inflammatory responses (11). Therefore, the renal protective activities of ZGR in this study were further confirmed by the anti-inflammatory activities of ZGR on the HMGB1-mediated severe vascular inflammatory responses (11).

The antioxidant enzymes, such as SOD, CAT, and GSH-Px, are considered to be the main defense against oxidative damage in tissues (25). Sepsis impaired the balance between free radical scavenging and cell antioxidant system production (26-27), and MDA is known as the major lipid peroxidation product and good index for oxidative stress (28-30). ZGR could be considered as a potential drug candidate for inflammatory renal diseases because SOD, CAT, GSH-Px, and MDA were positively controlled by ZGR in inflammatory renal tissues. Based on the current findings that ZGR reduced
CLP-induced production of inflammation-related proteins (IL-6 and TNF- $\alpha$ ), iNOS expression, and NO, which were accompanied by enhanced antioxidant defense system, we conclude that ZGR could be considered for the treatment of renal inflammatory diseases.

\section{MATERIALS AND METHODS}

\section{Reagents}

ZGR was purchased from Sigma (St. Louis, MO). Nuclear and cytoplasmic protein extraction reagent kits were obtained from Thermo Scientific Company (Rockford, IL). Antibodies against

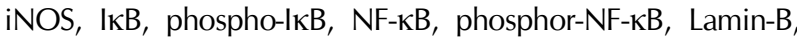
and $\beta$-actin were purchased from Cell Signaling Technology (Danvers, MA).

\section{Animals and cecal ligation and puncture}

Male C57BL/6 mice (6-7 weeks old) were obtained from Orient Bio Co. (Sungnam, Republic of Korea) and were given a $12 \mathrm{~d}$ acclimatization period. The mice were housed under controlled temperature $\left(20-25^{\circ} \mathrm{C}\right)$ and humidity conditions (40-45\% RH), with a $12 \mathrm{~h}$ light: $12 \mathrm{~h}$ dark cycle. They were fed a normal rodent pellet diet and had ad libitum access to water during acclimatization. To induce sepsis, the mice were first anesthetized with Zoletil (tiletamine and zolazepam, 1:1 mixture, $30 \mathrm{mg} / \mathrm{kg}$ ) and Rompum (xylazine, $10 \mathrm{mg} / \mathrm{kg}$ ). Sepsis was induced using cecal ligation and puncture (CLP) as previously described (31-32). As controls, sham-operated animals were used: in these mice, the cecum was exposed, but not ligated or punctured, and then returned to the abdominal cavity. Animals were randomly divided into 7 treatment groups ( $\mathrm{n}=10$ each): sham-operated control; ZGR-only (0.72 $\mathrm{mg} / \mathrm{kg}$ body weight) in $0.5 \%$ DMSO; CLP surgery only; and CLP + ZGR $(0.07,0.14,0.29$, or $0.72 \mathrm{mg} / \mathrm{kg}$ body weight). ZGR was intravenously injected at $12 \mathrm{~h}$ after CLP and again at $50 \mathrm{~h}$ after CLP. Blood and organ samples were collected 4 days after ZGR injection for functional assays. This protocol was approved by the Animal Care Committee at Kyungpook National University prior to conducting the study (IRB No. KNU 2017-102).

\section{Sample preparation}

Four days after ZGR injection, the mice were anesthetized as described above and sacrificed. Blood samples were collected from the posterior vena cava and allowed to clot. Serum was separated by centrifugation at 4,000 rpm for $10 \mathrm{~min}$, stored at $-80^{\circ} \mathrm{C}$ until analyzed and was used for the assessment of plasma BUN and creatinine levels. Kidney samples were immediately removed and weighed. The kidneys were then minced with scissors and homogenized in $0.1 \mathrm{M}$ phosphate buffer saline $(\mathrm{pH}$ 7.4); the tissue was fractionated under refrigeration by centrifugation at $10,000 \times \mathrm{g}$ for $10 \mathrm{~min}$. The homogenate was stored at $-80^{\circ} \mathrm{C}$ until analyzed in the various biochemical assays. Protein concentrations were 
determined using the Bradford assay.

\section{Evaluation of nephrotoxicity and lactate dehydrogenase}

Renal dysfunction was assessed by measuring the changes in levels of BUN and creatinine, and of protein in urine. BUN, creatinine, and lactate dehydrogenase (LDH), another important marker of tissue injury, were measured using commercial assay kits (Pointe Scientific, Linclon Park, MI). Urine samples were collected from each animal using a metabolic cage at 12 $\mathrm{h}$ after CLP surgery and the supernatant was obtained. Urinary protein concentrations were determined by the Bradford assay, using BSA as the protein standard.

\section{Plasma nitrite/nitrate determination}

Nitrite and nitrate concentrations in the plasma were determined using Griess reagents and vanadium solution $\left(\mathrm{VCl}_{3}\right)$ as previously described (33). Briefly, $100 \mu \mathrm{l}$ of $\mathrm{VCl}_{3}$ were added to $100 \mu \mathrm{l}$ of sample, immediately followed by Griess reagents $(0.1 \% \mathrm{~N}-1$-naphthylethylenediamine dihydrochloride and $1 \%$ sulfanilamide in $5 \%$ phosphoric acid). After 30 min of color development, absorbance was determined by measuring optical density (OD) at $540 \mathrm{~nm}$ using a microplate reader (Tecan Austria $\mathrm{GmbH}$, Austria). Concentrations were determined by comparing absorptions with those of a standard curve of sodium nitrite.

\section{ELISA for TNF- $\alpha$, IL-6, and HO-1}

The plasma concentrations of IL-6, TNF- $\alpha, \mathrm{HO}-1$ were determined using ELISA kits (R\&D Systems, Minneapolis, MN). Values were measured using an ELISA plate reader (Tecan, Austria $\mathrm{GmbH}$, Austria).

\section{Renal myeloperoxidase activity}

Renal myeloperoxidase (MPO) activity was used as a quantitative indicator for neutrophil influx into the kidney; MPO activity was measured using ELISA kits (Abcam, UK).

\section{Evaluation of oxidative stress markers}

Lipid peroxidation was determined using a method to measure the formation of thiobarbituric acid reactive substances (TBARSs). The level of malondialdehyde (MDA) in kidney tissue was measured spectrophotometrically using an OxiSelect TBARS assay kit (Cell Biolabs, San Diego, CA). MDA values were expressed as $\mathrm{nM} / \mathrm{mg}$ protein. Total glutathione (GSH) contents of kidney tissue were measured as described previously (34). A tissue homogenate was prepared, and then samples were added to metaphosphoric acid and allowed to stand for $5 \mathrm{~min}$ to precipitate proteins. Phosphate buffer and 5,5'-dithiobis-2-nitro-benzoic acid were added for color development. GSH was determined by measuring absorbance at $415 \mathrm{~nm}$ and absolute concentrations were calculated using a GSH standard (Sigma Aldrich, St. Louis, MO). Values of total GSH were expressed as $\mathrm{nM} / \mathrm{mg}$ protein. Superoxide dismutase (SOD) activity was measured using a SOD assay kit (Fluka).
Values of SOD were expressed as U/mg protein. Glutathione peroxidase (GSH-Px) activity was determined using the cellular activity assay kit CGP-1 (Sigma Aldrich). Values of GSH-Px were expressed as $\mathrm{U} / \mathrm{mg}$ protein. Catalase activity (CAT) was determined by a CAT assay kit (Sigma Aldrich) using the decomposition rate of the substrate $\mathrm{H}_{2} \mathrm{O}_{2}$ as determined at 240 $\mathrm{nm}$. Total CAT values were expressed as $\mathrm{U} / \mathrm{mg}$ protein.

\section{Westem blots from renal tissue}

Kidney samples were homogenized with radioimmunoprecipitation (RIPA) buffer containing protease inhibitors; equal amounts of protein were separated by SDS-PAGE $(10 \%)$ and were electroblotted overnight onto an Immobilon membrane (Millipore, Billerica, MA). Or, nuclear and cytoplasmic protein was prepared using extraction kit (Thermo Scientific Company, Rockford, IL). The membranes were blocked for $1 \mathrm{~h}$ with $5 \%$ low-fat milk-powder TBS (50 mM Tris-HCl, pH 7.5, 150 mM $\mathrm{NaCl}$ ) containing $0.05 \%$ Tween 20 and were then incubated with primary antibodies for iNOS, I $\mathrm{KB}$, phospho- $\mathrm{\kappa B}$,

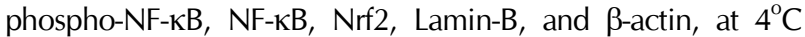
overnight. Subsequently, the membranes were incubated with horseradish-peroxidase-conjugated secondary antibody, and enhanced chemiluminescence (ECL) detection was performed according to the manufacturer's instructions.

\section{Cell culture}

Primary human umbilical vein endothelial cells (HUVECs) were obtained from Cambrex Bio Science (Charles City, IA) and maintained as previously described $(31,35)$. HUVECs at passages 3-5 were used.

\section{Statistical analysis}

All experiments were performed independently at least three times. Values are expressed as means \pm standard deviation (SD). The statistical significance of differences between test groups was evaluated using SPSS for Windows, version 16.0 (SPSS, Chicago, IL). Statistical relevance was determined by one-way analysis of variance (ANOVA) and Tukey's post-hoc test. P values less than 0.05 were considered to indicate significance.

\section{ACKNOWLEDGEMENTS}

This research was supported by a grant from the Korea Health Technology R\&D Project through the Korea Health Industry Development Institute (KHIDI), funded by the Ministry of Health \& Welfare, Republic of Korea (Grant number: HI15C0001), by the Bio \& Medical Technology Development Program of the National Research Foundation (NRF) funded by the Korea government (MSIT, 2017M3A9G8083382 and 2018R1A5A2025272).

\section{CONFLICTS OF INTEREST}

The authors have no conflicting interests. 


\section{REFERENCES}

1. Russell JA (2006) Management of sepsis. N Engl J Med $355,1699-1713$

2. Singer M, Deutschman CS, Seymour CW et al (2016) The Third International Consensus Definitions for Sepsis and Septic Shock (Sepsis-3). JAMA 315, 801-810

3. Chaudhry H, Zhou J, Zhong Y et al (2013) Role of cytokines as a double-edged sword in sepsis. In Vivo 27, 669-684

4. Parratt JR (1998) Nitric oxide in sepsis and endotoxaemia. J Antimicrob Chemother 41 Suppl A, 31-39

5. Symeonides S and Balk RA (1999) Nitric oxide in the pathogenesis of sepsis. Infect Dis Clin North Am 13, 449-463, $x$

6. Draisma A, Dorresteijn MJ, Bouw MP, van der Hoeven JG and Pickkers P (2010) The role of cytokines and inducible nitric oxide synthase in endotoxemia-induced endothelial dysfunction. J Cardiovasc Pharmacol 55, 595-600

7. Vincent JL, Zhang H, Szabo C and Preiser JC (2000) Effects of nitric oxide in septic shock. Am J Respir Crit Care Med 161, 1781-1785

8. Cadenas S and Cadenas AM (2002) Fighting the stranger-antioxidant protection against endotoxin toxicity. Toxicology 180, 45-63

9. Park KK, Chun KS, Lee JM, Lee SS and Surh YJ (1998) Inhibitory effects of [6]-gingerol, a major pungent principle of ginger, on phorbol ester-induced inflammation, epidermal ornithine decarboxylase activity and skin tumor promotion in ICR mice. Cancer Lett 129, 139-144

10. Sies $\mathrm{H}$ and Masumoto $\mathrm{H}$ (1997) Ebselen as a glutathione peroxidase mimic and as a scavenger of peroxynitrite. Adv Pharmacol 38, 229-246

11. Lee W, Ku SK and Bae JS (2017) Zingerone reduces HMGB1-mediated septic responses and improves survival in septic mice. Toxicol Appl Pharmacol 329, 202-211

12. Kim MK, Chung SW, Kim DH et al (2010) Modulation of age-related NF-kappaB activation by dietary zingerone via MAPK pathway. Exp Gerontol 45, 419-426

13. Rao BN, Archana PR, Aithal BK and Rao BS (2011) Protective effect of zingerone, a dietary compound against radiation induced genetic damage and apoptosis in human lymphocytes. Eur J Pharmacol 657, 59-66

14. Hemalatha KL and Prince PS (2015) Preventive effects of zingerone on altered lipid peroxides and nonenzymatic antioxidants in the circulation of isoproterenol-induced myocardial infarcted rats. J Biochem Mol Toxicol 29, 63-69

15. Banji D, Banji OJ, Pavani B, Kranthi Kumar C and Annamalai AR (2014) Zingerone regulates intestinal transit, attenuates behavioral and oxidative perturbations in irritable bowel disorder in rats. Phytomedicine 21, 423-429

16. Lee IC, Kim DY and Bae JS (2017) Inhibitory Effect of Zingerone on Secretory Group IIA Phospholipase A2. Nat Prod Commun 12, 929-932

17. Lee W, Ku SK, Kim MA and Bae JS (2017) Anti-factor Xa activities of zingerone with anti-platelet aggregation activity. Food Chem Toxicol 105, 186-193

18. Agca CA, Tuzcu M, Hayirli A and Sahin K (2014) Taurine ameliorates neuropathy via regulating NF-kappaB and $\mathrm{Nrf} / \mathrm{HO}-1$ signaling cascades in diabetic rats. Food Chem
Toxicol 71, 116-121

19. Yu M, Xu M, Liu Y et al (2013) Nrf2/ARE is the potential pathway to protect Sprague-Dawley rats against oxidative stress induced by quinocetone. Regul Toxicol Pharmacol 66, 279-285

20. Huber-Lang M, Sarma VJ, Lu KT et al (2001) Role of C5a in multiorgan failure during sepsis. J Immunol 166, 1193-1199

21. Bhargava R, Altmann CJ, Andres-Hernando A et al (2013) Acute lung injury and acute kidney injury are established by four hours in experimental sepsis and are improved with pre, but not post, sepsis administration of TNF-alpha antibodies. PLoS One 8, e79037

22. Guo RF and Ward PA (2006) C5a, a therapeutic target in sepsis. Recent Pat Antiinfect Drug Discov 1, 57-65

23. Stearns-Kurosawa DJ, Osuchowski MF, Valentine C, Kurosawa S and Remick DG (2011) The pathogenesis of sepsis. Annu Rev Pathol 6, 19-48

24. Oeckinghaus A and Ghosh S (2009) The NF-kappaB family of transcription factors and its regulation. Cold Spring Harb Perspect Biol 1, a000034

25. Birben E, Sahiner UM, Sackesen C, Erzurum S and Kalayci O (2012) Oxidative stress and antioxidant defense. World Allergy Organ J 5, 9-19

26. Horton JW (2003) Free radicals and lipid peroxidation mediated injury in burn trauma: the role of antioxidant therapy. Toxicology 189, 75-88

27. Hatwalne MS (2012) Free radical scavengers in anaesthesiology and critical care. Indian J Anaesth 56, 227-233

28. Qiao Y, Bai XF and Du YG (2011) Chitosan oligosaccharides protect mice from LPS challenge by attenuation of inflammation and oxidative stress. Int Immunopharmacol 11, 121-127

29. Zhang J, Yu Y, Zhang Z, Ding Y, Dai X and Li Y (2011) Effect of polysaccharide from cultured Cordyceps sinensis on immune function and anti-oxidation activity of mice exposed to 60Co. Int Immunopharmacol 11, 2251-2257

30. Xiao JH, Xiao DM, Chen DX, Xiao Y, Liang ZQ and Zhong JJ (2012) Polysaccharides from the Medicinal Mushroom Cordyceps taii Show Antioxidant and Immunoenhancing Activities in a D-Galactose-Induced Aging Mouse Model. Evid Based Complement Alternat Med 2012, 273435

31. Jung B, Kang H, Lee $W$ et al (2016) Anti-septic effects of dabrafenib on HMGB1-mediated inflammatory responses. BMB Rep 49, 214-219

32. Wang $H$, Liao $H$, Ochani $M$ et al (2004) Cholinergic agonists inhibit HMGB1 release and improve survival in experimental sepsis. Nat Med 10, 1216-1221

33. Miranda KM, Espey MG and Wink DA (2001) A rapid, simple spectrophotometric method for simultaneous detection of nitrate and nitrite. Nitric Oxide 5, 62-71

34. Beutler E, Duron O and Kelly BM (1963) Improved method for the determination of blood glutathione. J Lab Clin Med 61, 882-888

35. Kim J and Bae JS (2016) ROS homeostasis and metabolism: a critical liaison for cancer therapy. Exp Mol Med 48, e269 